\title{
The EPIYA-ABCC motif pattern in CagA of Helicobacter pylori is associated with peptic ulcer and gastric cancer in Mexican population
}

Fredy Omar Beltrán-Anaya ${ }^{1 \dagger}$, Tomás Manuel Poblete ${ }^{1 \dagger}$, Adolfo Román-Román ${ }^{1}$, Salomón Reyes², José de Sampedro ${ }^{3}$, Oscar Peralta-Zaragoza ${ }^{4}$, Miguel Ángel Rodríguez ${ }^{5}$, Oscar del Moral-Hernández ${ }^{5}$, Berenice Illades-Aguiar ${ }^{5}$ and Gloria Fernández-Tilapa ${ }^{1 *+}$

\begin{abstract}
Background: Helicobacter pylori chronic infection is associated with chronic gastritis, peptic ulcer, and gastric cancer. Cytotoxin-associated gene A (cagA)-positive H. pylori strains increase the risk of gastric pathology. The carcinogenic potential of CagA is linked to its polymorphic EPIYA motif variants. The goals of this study were to investigate the frequency of cagA-positive Helicobacter pylori in Mexican patients with gastric pathologies and to assess the association of cagA EPIYA motif patterns with peptic ulcer and gastric cancer.

Methods: A total of 499 patients were studied; of these, 402 had chronic gastritis, 77 had peptic ulcer, and 20 had gastric cancer. H. pylori DNA, cagA, and the EPIYA motifs were detected in total DNA from gastric biopsies by PCR. The type and number of EPIYA segments were determined by the electrophoretic patterns. To confirm the PCR results, 20 amplicons of the cagA $3^{\prime}$ variable region were sequenced, and analyzed in silico, and the amino acid sequence was predicted with MEGA software, version 5. The odds ratio (OR) was calculated to determine the associations between the EPIYA motif type and gastric pathology and between the number of EPIYA-C segments and peptic ulcers and gastric cancer.

Results: H. pylori DNA was found in 287 (57.5\%) of the 499 patients, and 214 (74\%) of these patients were cagA-positive. The frequency of cagA-positive H. pylori was 74.6\% (164/220) in chronic gastritis patients, $73.6 \%$ (39/53) in peptic ulcer patients, and $78.6 \%(11 / 14)$ in gastric cancer patients. The EPIYA-ABC pattern was more frequently observed in chronic gastritis patients $(79.3 \%, 130 / 164)$, while the EPIYA-ABCC sequence was more frequently observed in peptic ulcer $(64.1 \%$, $25 / 39)$ and gastric cancer patients $(54.5 \%, 6 / 11)$. However, the risks of peptic ulcer $(\mathrm{OR}=7.0,95 \% \mathrm{Cl}=3.3-15.1 ; \mathrm{p}<0.001)$ and gastric cancer $(\mathrm{OR}=5.9,95 \% \mathrm{Cl}=1.5-22.1)$ were significantly increased in individuals who harbored the EPIYA-ABCC cagA gene pattern.
\end{abstract}

Conclusions: cagA-positive H. pylori is highly prevalent in southern Mexico, and all CagA variants were of the western type. The cagA alleles that code for EPIYA-ABCC motif patterns are associated with peptic ulcers and gastric cancer.

Keywords: cagA gene 3' region, CRPIA, EPIYA, CagA, H. pylori

\footnotetext{
* Correspondence: gferti@hotmail.com

${ }^{\dagger}$ Equal contributors

${ }^{1}$ Clinical Research Laboratory, Academic Unit of Chemical-Biological Sciences, Autonomous University of Guerrero, Chilpancingo, Guerrero C.P. 39090,

Mexico

Full list of author information is available at the end of the article
} 


\section{Background}

Chronic Helicobacter pylori infection is etiologically related to chronic gastritis, gastric ulcers, and gastric cancer [1-4]. Cytotoxin-associated gene A (CagA)-producing strains seem to induce gastrointestinal disease more frequently than non-producing strains $[5,6]$. While the presence of CagA does not explain the variability in the clinical results, this oncoprotein is associated with severe gastroduodenal pathology [7-15]. CagA-positive strains are known to induce more intense gastric mucosal inflammation compared to cagA-negative strains. This pro-inflammatory potential of cagA-positive $H$. pylori could explain its association with severe atrophic gastritis and gastric adenocarcinoma $[16,17]$. The CagA oncoprotein is released within epithelial cells via a type IV secretion system $[18,19]$. Upon translocation, CagA localizes to the internal surface of the plasma membrane, where it is phosphorylated on C-terminal variable region tyrosine residues by multiple host Src tyrosine kinase family member proteins [20-22]. The phosphorylation motifs are defined by the Glu-Pro-Ile-Tyr-Ala (EPIYA) sequence and are classified as EPIYA-A, B, C, or D according to the amino acids that flank these motifs. Western CagA strains have the A and B segments and 1 or more $C$ segments. CagA strains from Eastern Asia have the A, B, and D segments. This explains the size variability of CagA proteins (range, $120-145 \mathrm{kDa}$ ) [3,9,23]. The main phosphorylation target in CagA is the tyrosine in the EPIYA-C and EPIYA-D motifs. The phosphorylation level is proportional to the number of EPIYA-C motifs, and thus, increased motif numbers increase the pro-inflammatory and carcinogenic potential of the protein. Phosphorylated CagA forms complexes with the SHP-2 phosphatase, resulting in abnormal signaling. This leads to subsequent cellular alterations that increase the risk of cells altered by precancerous genetic changes [3,23-28]. In epithelial cells, SHP-2 binds more tightly to EPIYA-D than to EPIYA-C. However, CagA proteins with EPIYA-ABCCC have the same carcinogenic potential as those with EPIYA-D [25]. Western CagA-producing H. pylori strains with EPIYA-C sequences are more virulent and carcinogenic than CagAproducing strains with EPIYA-A and B motifs [15,29,30].

The prevalence of cagA-positive $H$. pylori is $90-95 \%$ in Asian countries and $50-60 \%$ in western countries $[3,23]$. CagA genotype distribution varies among regions and ethnic groups. For example, the Amerindian (AM) cagA allelic variants, which are found in the inhabitants of the Peruvian Shimaa village, encode CagA isoforms that contain altered or degenerate EPIYA-B motifs, specifically ESIYT in AM-I and GSIYD in AM-II. Additionally, the AM CagA contains attenuated conserved repeats that are responsible for phosphorylation-independent activity (CRPIA). The AM strains have attenuated proliferation and induce low-grade inflammation, resulting in low virulence and a decreased risk of severe pathology [26,31].
CagA is one of the most studied genes worldwide. In Mexico, the seroprevalence of cagA-positive $H$. pylori varies between $40 \%$ and $90 \%$ in patients with gastric pathology from different zones throughout the country [8,32-36]. In patients from Mexico City who presented gastroduodenal pathology, the EPIYA segments of $\operatorname{cag} A$-positive strain were of the western type [37]. In another study conducted in children with abdominal pain and adults with duodenal ulcers, gastric ulcers, or non-ulcerous dyspepsia, the identified EPIYA patterns were $\mathrm{ACC}, \mathrm{ABC}, \mathrm{ABCC}, \mathrm{ABCCC}$, and $\mathrm{ABABC}$ [37]. The following sequences were identified in gastric cancer and chronic gastritis cases: $\mathrm{ABC}, \mathrm{ABCC}$, ABABC, $A A B C C$, and $A B C C C$ [38]. However, to date, no studies have been conducted to explore the association between the type and number of EPIYA segments and severe gastric pathologies in southern Mexico. The analysis of the association between the EPIYA-C motif number and peptic ulcers and gastric cancer, will help to clarify the relationship between CagA variants and gastric disease severity in $H$. pylori-infected Mexican patients. The goal of this study was to investigate the prevalence of cagApositive $H$. pylori and the EPIYA motif types in the gastric mucosa of patients with chronic gastritis, peptic ulcers, and gastric cancer to determine whether the EPIYA-C motif number is associated with ulcers and gastric cancer.

In this study, we found a high prevalence of westerntype cagA-positive $H$. pylori infection, with a predominant EPIYA-ABCC pattern in Mexican patients with peptic ulcers and gastric cancer. Interestingly, the presence of a CagA protein with 2 or more EPIYA-C motifs was associated with severe gastric pathology.

\section{Methods \\ Patients}

A total of 499 patients were studied. The study subjects were sequentially selected from patients who suffered from dyspepsia symptoms and had been subjected to upper gastrointestinal tract endoscopy at the Chilpancingo's General Hospital "Dr. Raymundo Abarca Alarcón" or at the State Institute of Oncology in Acapulco, Guerrero, Mexico. The subjects were recruited between April 18, 2007 and April 19, 2013. Patients in this study had not received treatment with antimicrobial agents, proton pump inhibitors, or gastric $\mathrm{pH}$-neutralizing agents for a month before the endoscopic treatment. Patients who received immunosuppressive or non-steroid anti-inflammatory treatment were excluded from the study. Either the patients or their parents signed an informed consent letter. This project was approved by the Bioethics Committee of the Autonomous University of Guerrero and the participating hospitals. 


\section{Biopsy collection}

Endoscopies were conducted after an overnight fast with a video processor and a video gastroscope (Fujinon, Wayne, NJ, USA). Two biopsies from the gastric antrum or body, the ulcer edge, or the tumor were collected. One biopsy was immediately fixed in 10\% formalin for histological analysis, while the other was placed in a buffered solution $(10 \mathrm{mM}$ Tris, $\mathrm{pH}$ 8.0, $20 \mathrm{mM}$ EDTA, $\mathrm{pH}$ 8.0, 0.5\% SDS) for the molecular diagnosis of $H$. pylori. The latter biopsies were stored at $-20^{\circ} \mathrm{C}$ until processing.

\section{Histology}

The formalin-fixed biopsies were embedded in paraffin, and $4-\mu \mathrm{m}$ sections were stained with hematoxylin-eosin for histological analysis. Histopathological findings were used to determine each patient's diagnosis. Gastritis was classified according to the updated Sydney system.

\section{H. pylori detection}

Total DNA was extracted from gastric biopsies according to the phenol-chloroform-iso-amyl alcohol technique after proteinase K digestion [39]. The specific presence of the $H$. pylori $16 \mathrm{~S}$ rRNA gene was assessed according to the methods previously described by Román-Román et al. [40]. For all reactions, DNA samples from the cagA-positive ATCC43504 and $599 \mathrm{H}$. pylori strains were used as positive controls. For negative controls, DNA was substituted with sterile deionized water. All reactions were performed in a Mastercycler Ep gradient thermocycler (Eppendorf, Hamburg, Germany).

\section{CagA gene amplification}

H. pylori $16 \mathrm{~S}$ rRNA gene-positive samples were subjected to PCR to detect the cagA gene using the primers described previously by Figura et al., [9]. These oligonucleotides amplified a 298-bp fragment within the constant region [9]. To amplify a 550- to $850-$ bp region within the 3 ' variable region of the cagA gene the primers cag2 and cag4 described previously by Argent et al., were using $[41,42]$, Table 1 . The reaction mix consisted of $1.7 \mathrm{mM}$ $\mathrm{MgCl}$, $0.2 \mathrm{mM}$ dNTPs (Invitrogen, Carlsbad, CA, USA),
5 pmol of each oligonucleotide, $1 \mathrm{U}$ of Platinum ${ }^{\odot}$ Taq DNA polymerase (Invitrogen Carlsbad, CA, USA), and $300 \mathrm{ng}$ of total DNA in a total volume of $25 \mu \mathrm{l}$. The following amplification conditions were used: 1 cycle at $94^{\circ} \mathrm{C}$ for $5 \mathrm{~min}$; 30 cycles at $94^{\circ} \mathrm{C}$ for $40 \mathrm{~s}, 56^{\circ} \mathrm{C}$ for $30 \mathrm{~s}$, and $72^{\circ} \mathrm{C}$ for $50 \mathrm{~s}$; and a final extension cycle at $72^{\circ} \mathrm{C}$ for $10 \mathrm{~min}$. The PCR products were subjected to electrophoresis on a $1.5 \%$ agarose gel, followed by ethidium bromide staining and analysis under an ultraviolet (UV) light. Samples were considered CagA-positive when at least 1 of the 2 bands was observed.

\section{Amplification of the cagA gene 3 ' variable region and EPIYA motif prediction}

Each cagA-positive sample was subjected to 4 PCR reactions to identify the EPIYA motifs. The sense oligonucleotide primer cag28F was used in all 4 reactions, while the antisense oligonucleotide primers cagA-P1C, cagAP2TA [41], CagAWest, and CagAEast [42] were used in separate reactions to amplify the EPIYA-A ( 264 bp), B ( 306 bp), C ( $501 \mathrm{bp})$, and D (495 bp) motifs, respectively, Table 1. All PCR samples were prepared with $0.2 \mathrm{mM}$ dNTPs (Invitrogen Carlsbad, CA, USA), $1.5 \mathrm{mM} \mathrm{MgCl}_{2}, 10 \mathrm{pmol}$ of each oligonucleotide, $1 \mathrm{U}$ of Platinum ${ }^{\odot}$ Taq DNA Polymerase (Invitrogen Carlsbad, CA, USA), and $300 \mathrm{ng}$ of total gastric biopsy DNA in a final volume of $25 \mu$ l. The following amplification conditions were used: 1 cycle at $94^{\circ} \mathrm{C}$ for $5 \mathrm{~min} ; 35$ cycles at $94^{\circ} \mathrm{C}$ for $1 \mathrm{~min}, 58^{\circ} \mathrm{C}$ for $30 \mathrm{~s}$, and $72^{\circ} \mathrm{C}$ for $1 \mathrm{~min}$; and a final extension cycle at $72^{\circ} \mathrm{C}$ for $10 \mathrm{~min}$. The PCR products were separated by electrophoresis on a $1.5 \%$ agarose gel, followed by ethidium bromide staining and UV light analysis.

\section{Sequencing and bioinformatics analysis of the cagA gene 3 ' variable region}

A subset of 20 samples was randomly selected for sequencing to confirm the PCR results. Cag28F and cag4 primers were used to amplify the variable region and generate $\sim 650$ to $\sim 850$-bp amplicons. The PCR reaction was conducted in a $50-\mu \mathrm{l}$ volume with $15 \mathrm{pmol}$ of each primer, $0.3 \mathrm{mM}$ dNTPs, $2 \mathrm{mM} \mathrm{MgCl}_{2}$, and $1 \mathrm{U}$ of Platinum ${ }^{\oplus}$ Taq DNA

Table 1 PCR primers used in this study

\begin{tabular}{|c|c|c|c|}
\hline Primer name and reference & Primer sequence (5'to $3^{\prime}$ ) & Motif amplied & Size (bp) \\
\hline cagAF D008 [9] & ACAATGCTAAATTAGACAACTTGAGCGA & Constant region of the cagA gene & 298 \\
\hline cagAR R008 [9] & TTAGAATAATCAACAAACATCACGCCAT & & \\
\hline $\operatorname{cag} 2 \mathrm{~F}[30,41]$ & GGAACCCTAGTCGGTAATG & $\operatorname{cag} A 3^{\prime}$ variable region & 550 to 850 \\
\hline cag4 $[30,41]$ & ATCTTTGAGCTTGTCTATCG & & \\
\hline $\operatorname{cagA28F}[41]$ & TTCTCAAAGGAGCAATTGGC & Forward for all EPIYA motifs & \\
\hline $\operatorname{cagA-P1C}[41,42]$ & GTCCTGCTTTCTITITATTAACTTKAGC & $E P / Y A-A$ & 264 \\
\hline $\operatorname{cagA-P2TA}[41,42]$ & TTAGCAACTTGAGTATAAATGGG & $E P / Y A-B$ & 306 \\
\hline cagAWest [42] & TITCAAAGGGAAAGGTCCGCC & $E P / Y A-C$ & 501 \\
\hline cagAEast [42] & AGAGGGAAGCCTGCTTGATT & EPIYA-D & 495 \\
\hline
\end{tabular}


Polymerase (Invitrogen Carlsbad, CA, USA) per reaction. The amplification conditions were as follows: 1 cycle at $94^{\circ} \mathrm{C}$ for $5 \mathrm{~min} ; 30$ cycles at $94^{\circ} \mathrm{C}$ for $40 \mathrm{~s}, 55.5^{\circ} \mathrm{C}$ for $30 \mathrm{~s}$, and $72^{\circ} \mathrm{C}$ for $50 \mathrm{~s}$; and a final extension cycle at $72^{\circ} \mathrm{C}$ for $7 \mathrm{~min}$. The PCR products were purified with the PureLink $^{\circ}$ PCR Purification Kit (Invitrogen Carlsbad, CA, USA) according to the manufacturer's instructions. The purified products were sequenced with the BigDye terminator v1.1 sequencing kit (Applied Biosystems, Foster City, CA, USA) and analyzed with an ABI PRISM 310 Genetic Analyzer (Applied Biosystems). The nucleotide sequences were transformed into amino acid sequences with MEGA v5 software [43]. The ClustalW option within the MEGA software was used to generate a multiple amino acid sequence alignment. The partial CagA protein sequence from the $H$. pylori strain 43526 (GenBank: AF001357.1) was used as a reference.

\section{Statistical analysis}

Kruskal-Wallis, ANOVA, $\chi^{2}$, and Fisher's exact test analyses were used to determine significant differences. Associations between the presence of $\mathrm{H}$. pylori, CagA, and the EPIYA-C motif number were determined in multinomial logistic regression models at a confidence interval of $95 \%$. A p-value $<0.05$ indicated statistical significance. All analyses were conducted with the Stata v11.1 software package (StataCorp, College Station, TX, USA).

\section{Results}

\section{Population characteristics}

Of the 499 studied patients, 402 (80.6\%) were diagnosed with chronic gastritis, 77 (15.4\%) with peptic ulcers, and $20(4 \%)$ with gastric cancer. The age of patients ranged from 11 to 80 years old. The cancer patients were significantly older $(p<0.001)$ than those in the other groups, and the female gender was predominant in all 3 groups.
Education years were significantly different among the groups $(\mathrm{p}<0.001)$, Table 2 .

\section{CagA status of Helicobacter pylori infections}

The presence of the $H$. pylori $16 \mathrm{~S}$ rRNA gene was detected in the gastric mucosa samples from 287 (57.5\%) patients. The difference in the infection frequencies according to the diagnosis was significant $(\mathrm{p}=0.037)$, and a higher prevalence was observed in gastric cancer patients $(70 \%)$, Figure $1 \mathrm{~A}$. The H. pylori cagA gene was found in 214 (74\%) of the 287 infected patients, Figure 1B. However, no significant differences in the frequencies of cagA-positive $H$. pylori were found among the study groups $(\mathrm{p}=0.930)$. The congruence between the two PCR assays for determining cagA status was $88 \%$ (Kappa correlation coefficient $=0.8857 \mathrm{p}<0.001$ ), data not shown

\section{EPIYA segments and EPIYA-C motif numbers}

The PCR products amplified from cagA-positive samples showed four electrophoretic patterns that corresponded to the following combinations of EPIYA motifs: $A B C$, $A B C C, A B B C$, and $A B B C C C$. The EPIYA-D motif was not detected, Figure 2.

The EPIYA-ABC segment was detected in 148 (69.2\%) patients, while the ABCC motif was detected in 64 (29.9\%) of the $214 \mathrm{H}$. pylori cagA-positive subjects. The EPIYA ABBCCC motif was only detected in one patient with chronic gastritis, while the $\mathrm{ABBC}$ motif was only detected in one patient with gastric cancer, Figure 1C. The EPIYA-ABC pattern was found in $130(79.3 \%)$ of the 164 cagA-positive H. pylori patients with chronic gastritis and was more frequent in this group than in ulcer and cancer. CagA-positive H. pylori with two EPIYA-C motifs was more frequently detected in patients with ulcers and gastric cancer $(64.1 \%$ and $54.6 \%$, respectively), Table 3, Figure $1 \mathrm{C}$. The results were confirmed by sequencing a $\sim 650$ - to $\sim 850$-bp fragment

Table 2 Sociodemographic characteristics in Mexican patients with chronic gastritis, peptic ulcers, and gastric cancer

\begin{tabular}{|c|c|c|c|c|}
\hline & \multicolumn{3}{|l|}{ Diagnosis } & \multirow[b]{2}{*}{$p$ value } \\
\hline & Chronic gastritisn = 402 & Peptic ulcern $=77$ & Gastric cancern $=20$ & \\
\hline Age (mean $\pm S D)$ & $47.4 \pm 16.7$ & $52.8 \pm 16.5$ & $58.7 \pm 16)$ & $0.0009^{\dagger}$ \\
\hline \multicolumn{5}{|l|}{ Gender n (\%) } \\
\hline Male & 155 (38.6) & $33(42.9)$ & $9(45)$ & \multirow[t]{2}{*}{$0.682^{\circ}$} \\
\hline Female & $247(61.4)$ & $44(57.1)$ & $11(55)$ & \\
\hline \multicolumn{5}{|l|}{ Smoking habit n (\%) } \\
\hline No & $239(59.5)$ & $36(41.8)$ & $10(50)$ & \multirow[t]{2}{*}{$0.096^{\diamond}$} \\
\hline Current smoker or former smoker & $163(40.5)$ & $41(53.2)$ & $10(50)$ & \\
\hline \multicolumn{5}{|l|}{ Alcohol consumption n (\%) } \\
\hline No & $100(24.9)$ & $22(28.6)$ & $6(30)$ & \multirow[t]{2}{*}{$0.716^{\diamond}$} \\
\hline Consumes or consumed & $302(75.1)$ & $55(71.4)$ & $14(70)$ & \\
\hline Education [median (ranges), years] & $12(6-17)$ & $12(6-17)$ & $6(0-7.5)$ & $0.0001^{-}$ \\
\hline
\end{tabular}

†ANOVA test; "Kruskal-Wallis test; $\diamond \mathrm{x}^{2}$ test. 


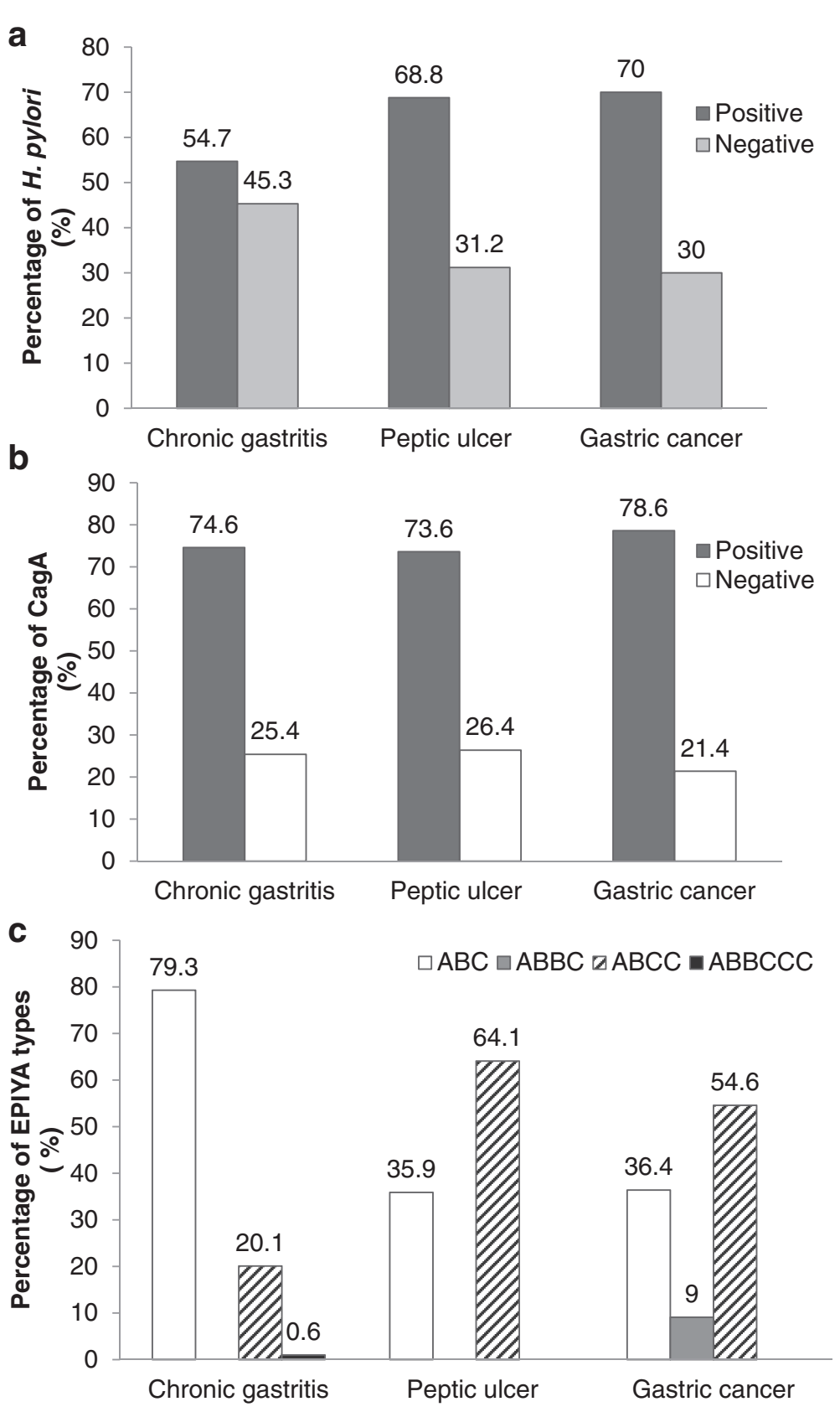

Figure 1 Prevalence of $H$. pylori, cagA, and EPIYA patterns according to histopathological diagnoses. A) Percentage of patients with $H$. pylori infection according to gastric disease. There were statistically significant differences in the prevalence of $H$. pylori among the study groups ( $p=0.037, X^{2}$ test). B) Percentage of cagA among patients with $H$. pylori infection. The prevalence of cagA-positive H. pylori was very similar among the study groups ( $p=0.930$, $X^{2}$ test). C) The prevalence of the different EPIYA patterns in the cagA gene is shown. The EPIYA-ABC and ABCC sequences were differentially distributed among patients with chronic gastritis, peptic ulcers, and gastric cancer ( $p=0.000$; Fisher's exact test).

within the $3^{\prime}$ variable region of the cagA gene in 20 randomly selected samples. The agreement between the results of PCR and sequencing was $100 \%$.

\section{Bioinformatic analysis of the CagA amino acid sequence} The cagA DNA sequences from the following amplicons were analyzed: 9 gastric cancer amplicons (MX02-C,
MX21-C, MX22-C, MX05-C, MX12-C, MX03-C, MX08C, MX17-C, MX16-C); 9 chronic gastritis amplicons (MX66-G, MX51-G, MX52-G, MX637-G, MX006-G, MX44-G, MX43-G, MX45-G, MX392-G) and two peptic ulcer amplicons (MX204-GU, MX327-GU). An in silico amino acid prediction was conducted to identify the EPIYA and CagA multimerization (CM, also known as 


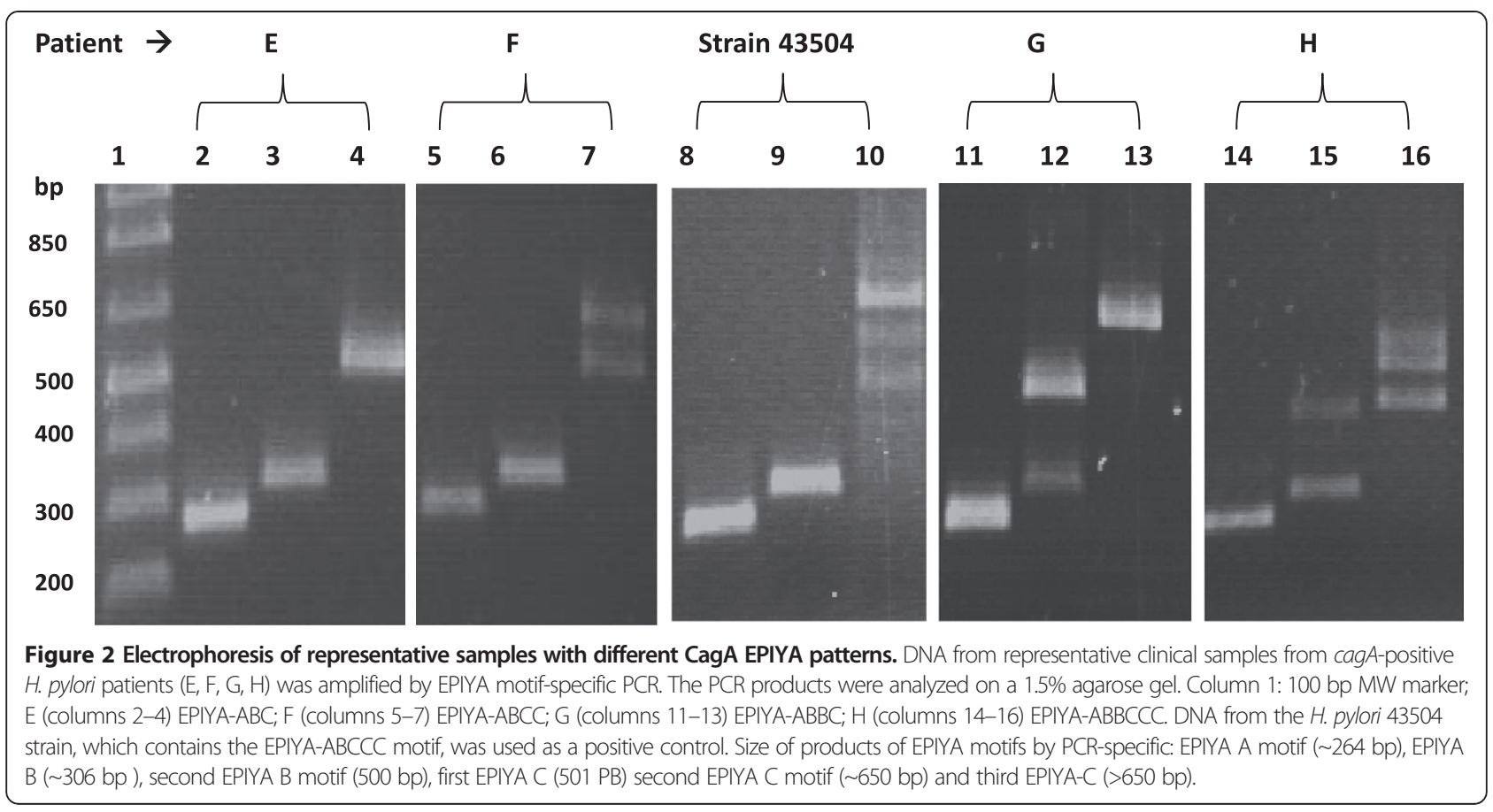

CRPIA) motifs [26]. The following motifs and corresponding patterns were found: EPIYA-A with the EPIYA(K/Q) VNKKK (A/T/V/S)GQ pattern, EPIYA-B with the E(P/S) $\operatorname{IY}(\mathrm{A} / \mathrm{T})(\mathrm{Q} / \mathrm{K}) \mathrm{VAKKV}(\mathrm{N} / \mathrm{T})(\mathrm{A} / \mathrm{Q}) \mathrm{KI}$ pattern, and EPIYA$\mathrm{C}$ with the EPIYATIDDLGGP pattern, Figure 3. Two EPIYA-B motif variants were found; one chronic gastritis sample (MX44-G) had an ESIYT sequence, while 10 (50\%) of the 20 sequences contained the EPIYT pattern (MX02C, MX22-C, MX05-C, MX637-G, MX03-C, MX08-C, MX327-GU, MX43-G, MX16-C). The following changes were found among the 16 amino acid residues that comprise the CRPIA motif: $\operatorname{FPLK}(\mathrm{R} / \mathrm{K}) \mathrm{H}(\mathrm{D} / \mathrm{G}) \mathrm{KVD}(\mathrm{D} / \mathrm{N})$ LSKVG for the first CRPIA motif in the N-terminus of EPIYA-C, FPLK(R/K)H(D/G)KVDDLSKVG for the second CRPIA motif, and FPLKRHDKVDDLSKV for the last CRPIA motif in the C-terminus. A CRPIA motif was identified in the N-terminus of one of the two EPIYA-B motifs in the CagA-containing MX16-C gastric cancer sample. Within this sequence, the amino acids GKDKGPE were found in the N-terminus of the EPIYA-A motif (Figure 3). All CRPIA motifs were of the western type, Figure 3 . Nucleotide and predict protein sequences of all strains were deposited in GenBank, accession numbers [GenBank: KF800898.1- GenBank:KF800917.1].

\section{Association between $H$. pylori infection, cagA-positive strains, peptic ulcers, and gastric cancer}

H. pylori infection was associated with peptic ulcers $(\mathrm{OR}=1.8 ; 95 \% \mathrm{CI}=1.0-3.0)$ but not with gastric cancer $(\mathrm{OR}=1.9 ; 95 \% \mathrm{CI}=0.72-5.1)$. On the other hand, infection with cagA-positive strains was not associated with either ulcers or gastric cancer, Table 3.

\section{Association between the EPIYA-C motifs number with peptic ulcers, and gastric cancer}

The presence of the EPIYA-ABCC segment was associated with peptic ulcers $(\mathrm{OR}=7.0 ; 95 \% \mathrm{CI}=3.3-15.1 ; \mathrm{p}<0.001)$ and gastric cancer $(\mathrm{OR}=5.9 ; 95 \% \mathrm{CI}=1.5-22.1 ; \mathrm{p}=0.008)$. The increase in the number of EPIYA-C repeats was also associated with peptic ulcers $(\mathrm{OR}=6.8 ; 95 \% \mathrm{CI}=3.2-15.6$; $\mathrm{p}<0.001)$, as well as cancer $(\mathrm{OR}=4.5 ; 95 \% \mathrm{CI}=1.3-15.9$; $\mathrm{p}=0.017$ ), Table 3 .

\section{Discussion}

Infection with a $\operatorname{cag} A$-positive $H$. pylori strain is recognized as the most important risk factor for gastric cancer and is also associated with atrophic gastritis and duodenal ulcers $[29,44]$. Nonetheless, the majority of infected patients do not develop serious diseases.

In the present study, we found that $57.5 \%$ of patients with gastric pathologies were $H$. pylori-positive, and $74 \%$ of the infecting strains harbored the cagA gene. The global prevalence of $c a g A$-positive $H$. pylori, which ranges from $43 \%$ to $90 \%$, is in accordance with the previously reported seroprevalence in a Mexican population with gastric pathologies [8,32-36]. However, serology might overestimate the frequency of $H$. pylori and cagA-positive strains as it is unable to differentiate between current and past infections. The discrepancies in the prevalence of $H$. pylori can be explained by differences in the diagnostic method used, age of patients, geographic area and the environmental 
Table 3 Association of H. pylori, cagA and EPIYA-C motif number with chronic gastritis, peptic ulcer and gastric cancer

\begin{tabular}{|c|c|c|c|c|}
\hline \multirow[b]{2}{*}{ Diagnosis } & \multicolumn{4}{|l|}{ H. pylori } \\
\hline & Negative & Positive & OR & $\mathrm{Cl} 95 \%$ \\
\hline G & 182 & 220 & 1.0 & - \\
\hline PU & 24 & 53 & $1.8^{c}$ & $1.0-3.0$ \\
\hline GC & 6 & 14 & 1.9 & $0.72-5.1$ \\
\hline \multirow[t]{3}{*}{ Total } & 212 & 287 & & \\
\hline & \multicolumn{4}{|l|}{ CagA } \\
\hline & Negative & Positive & OR & $\mathrm{Cl} 95 \%$ \\
\hline G & 56 & 164 & 1.0 & - \\
\hline PU & 14 & 39 & 0.9 & $0.5-1.9$ \\
\hline GC & 3 & 11 & 1.2 & $0.3-4.6$ \\
\hline \multirow[t]{3}{*}{ Total } & 73 & 214 & & \\
\hline & \multicolumn{4}{|c|}{ EPIYA motif } \\
\hline & $A B C$ & $A B C C$ & OR & IC95\% \\
\hline G & 130 & 33 & 1.0 & - \\
\hline PU & 14 & 25 & $7.0^{\mathrm{a}}$ & $3.3-15.1$ \\
\hline GC & 4 & 6 & $5.9^{\mathrm{b}}$ & $1.5-22.1$ \\
\hline \multirow[t]{3}{*}{ Total } & 148 & 64 & & \\
\hline & \multicolumn{4}{|c|}{ Number of EPIYA-C } \\
\hline & $1 C^{*}$ & $\geq 2 C^{\varphi}$ & OR & IC95\% \\
\hline G & 130 & 34 & 1.0 & - \\
\hline$P U$ & 14 & 25 & $6.8^{\mathrm{a}}$ & $3.2-15.6$ \\
\hline GC & 5 & 6 & $4.5^{\mathrm{c}}$ & $1.3-15.9$ \\
\hline Total & 149 & 65 & & \\
\hline
\end{tabular}

G; chronic gastritis, UP peptic ulcer, CG: gastric cancer. ${ }^{a} \mathrm{p}<0.001 ;{ }^{\mathrm{b}} \mathrm{p}<0.01$; ${ }^{c} p<0.05$. ${ }^{*}$ The EPIYA-ABBC was added; ${ }^{\varphi}$ the EPIYA-ABBCCC was added Note: Only the most frequent EPIYA motifs were considered.

health conditions in which people live. Another possible explanation is that the rate of infection is decreasing [36]. In our study, the prevalence of cagA-positive $H$. pylori in patients with chronic gastritis was higher (74.6\%) than the rate reported in 2009 by Paniagua et al. (52.4\%) via multiplex PCR [45]. In gastric cancer patients, the prevalence of cagA was higher (78.6\%) than the seroprevalence reported in 2008 by Carmolinga et al. (66.2\%) [8]. In this work, the frequency of $H$. pylori cagA-positive that we found was similar to antibodies prevalence in Mexican subjects and, unlike to other studies, the strengths of our study are in the sample size and the high sensitivity and specificity of the methods used to detect $H$. pylori and cagA.

Some authors have found an association between CagA and the severity of gastric pathologies [7,11-14]. It has been proposed that this relationship might be explained by the number of EPIYA-C motifs in the protein as these motifs influence the degree of virulence and oncogenic potential of cagA-positive $H$. pylori $[7,46]$. It is likely that determining the EPIYA motifs in CagA, rather than detecting cagA per se, would be a better marker for assessing the risk of serious gastric pathology [41,47]. In our study, $100 \%$ of the EPIYA motifs identified in CagA were of the western type, and their distributions among the pathologies were significantly different $(\mathrm{p} \leq 0.001)$. In $69.1 \%$ of the cases, the cagA gene contained an EPIYA-C motif in the typical $\mathrm{ABC}$ sequence, and this was more frequent in patients with chronic gastritis (79.3\%). This result was similar to that reported by Batista et al. for Brazilian populations $(70.6 \%$ in total of cases and $79.4 \%$ in patients with gastritis), [48] but higher than that found in Colombian patients by Quiroga et al. (49\% in total of cases and 59.6\% in patients with gastriris), [29] and by Acosta et al. (62.3\% in total of cases and $52.6 \%$, in gastritis) [49]. Interestingly, Rizzato et al. [38] detected the EPIYA-ABC pattern in $82 \%$ of Venezuelan and Mexican patients with chronic gastritis and gastric cancer, without finding frequency differences between the groups. Reyes-León et al. [37] found that the $\mathrm{ABC}$ sequence was more frequent $(50 \%)$ in children from Mexico City with chronic abdominal pain. These findings emphasize the differences in the geographic distribution of $H$. pylori strains, and these differences might be related to the uneven prevalence of gastric cancer in the inhabitants of different Mexican regions.

The frequency of cases that harbored cagA-positive $H$. pylori with two EPIYA-C motifs was higher in gastric cancer patients $(64 \%)$ and thus higher than the frequencies reported by Acosta (27.7\%) and Quiroga (35.3\%) in Colombia and by Batista in Brazil (34.6\%) [29,48,49]. We found that the cagA allele that encoded two EPIYA-C segments was also predominant in patients with peptic ulcers (54.5\%). This frequency is higher than that reported by Torres in Cuban patients (15.7\%) [50]. Unexpectedly, the only motif with three EPIYA-C repeats $(\mathrm{ABBCCC})$ was found in a patient with chronic gastritis. Reportedly, an increase in the number of phosphorylation sites in the C-terminus of CagA is associated with the carcinogenic potential of $H$. pylori $[15,37,49]$. Thus, it is likely that those patients with chronic gastritis infected with a $H$. pylori strain with cagA gene that encodes two or more EPIYA-C motifs $(21 \%)$ are at higher risk of developing more serious diseases.

The amino acid sequences obtained during a bioinformatics analysis revealed that the alanine-to-threonine substitution in the EPIYA-B (EPIYT) motif occurred frequently (10 out of 20 sequences) in the studied groups. These findings are in accordance with those reported by Rizzato et al. in 2012 for Mexican and Venezuelan subjects with chronic gastritis and gastric cancer (50\% of the B motifs harbored the EPIYT variant, with no significant differences between the groups) [38]. ABCC isolates bearing this modification have also been reported to cause decreased levels of cellular elongation and IL-8 secretion compared to those that bear 


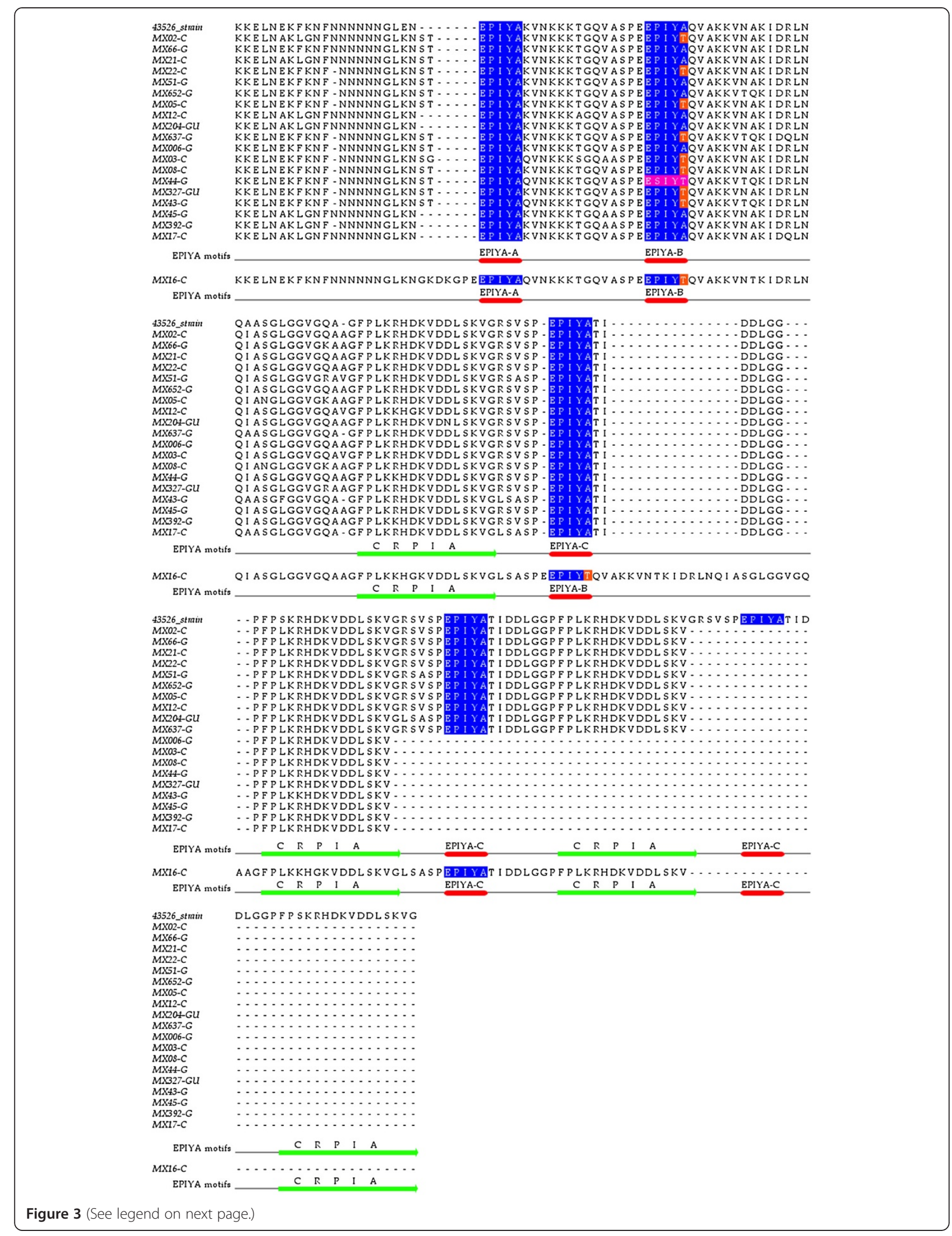


(See figure on previous page.)

Figure 3 Alignment of CagA sequences from patients with gastric disorders. CagA amino acid sequences obtained from nine patients with chronic gastritis (G), two with peptic ulcer (GU) and nine with gastric cancer (C) are aligned with the CagA sequence from H. pylori reference strain 43526. The sample number is followed by the histological diagnosis. The EPIYA amino acids are shown in blue. The red lines highlight each EPIYA pattern, and the green lines underline the CRPIA motifs. Alanine-to-threonine changes (EPIYT) in EPIYA-B are shown in orange. The ESIYT sequence that corresponds to the proline-to-serine and alanine-to-serine changes in EPIYA-B is shown in pink. An AM-I strain was detected in one patient with chronic gastritis (MX44-G [GenBank: KF800906.1]. The sample MX16-C [GenBank: KF800911.1] from patient with gastric cancer contain a CRPIA motif in the N-terminus of its second EPIYA-B. This sequence is unique in that it contain an extra EPIYA-B motif and an extra CRPIA motif, making it difficult to align it with CagA from strain 43526. GenBank accession numbers of each strain in this figure:MX02A-C [KF800917.1], MX66-G [KF800903.1], MX21-C[KF800909.1], MX22-C[KF800908.1 ], MX51-G[KF800904.1], MX652-G[KF800898.1], MX05-C[ KF800915.1], MX12-C[KF800912.1], MX204-GU[KF800902.1], MX637-G[ KF800899.1], MX006-G [KF800914.1], MX03-C[ KF800916.1], MX08T-C[KF800913.1], MX44-G[KF800906.1], MX327-GU[KF800901.1], MX43-G[KF800907.1], MX45-G[KF800905.1], MX392-G[KF800900.1], MX17-C[KF800910.1], MX16-C[KF800911.1].

the normal ABCC pattern [37]. It is possible that, in a Mexican population, the frequency of CagA isoforms with the EPIYT amino acid sequence in EPIYA-B is associated with the prevalence of gastroduodenal diseases. However, the existing epidemiological and experimental studies are insufficient to further support this hypothesis.

The ESIYT modification in EPIYA-B was identified in one chronic gastritis sample. This sequence belonged to the AM-I CagA variant, which has been associated with low $H$. pylori virulence in comparison to the western or Asian strains [26]. However, the AM-I and II CagA variants, such as those found in indigenous Mexican groups with Amerindian ancestry, show degeneration or elimination in their CRPIA motifs [26,31,51]. Interestingly, the CagA variants with the ESIYT sequence found in the present study contained western-type CRPIA and therefore differed from the Amerindian variants [31]. A CRPIA sequence in the Nterminus of the EPIYA-B motif was also detected in a gastric cancer sample. This finding agrees with those reported by Sicinschi et al., Sgouras et al. and Acosta et al., who noted that in some CagA variants, the CRPIA segment can be found in the N-termini of the EPIYA-A and B motifs $[15,49,52]$. The localization of the CRPIA motif within EPIYA-B might result from recombination between $H$. pylori strains with different cagA allelotypes or from the insertion of DNA sequences that contribute to $H$. pylori diversification [53,54]. The CRPIA sequences stabilize the CagA protein, influence its half-life and are associated with oncoprotein activity in epithelial cells [15]. Thus, our results highlight the need to evaluate the functional importance of the EPIYT and ESIYT variants in EPIYA-B. Furthermore, it is necessary to assess the effects that the observed sequence variants and the localization of the CRPIA motifs in the ABCC pattern exert on CagA activity. It is likely that the prevalence of some of these variants could explain why the gastric cancer incidence rates of male and female Mexican patients (9.4 and 6.7/100,000, respectively) are similar to those reported in Southeastern Asian countries (10.2 and 4.7/100,000 in men and women, respectively) [55], despite the differences in the cagA-positive $H$. pylori prevalence (90-95\% in Japan, Korea, and China; 50-60\% in Mexico).
The association of cagA polymorphisms with severe gastric pathologies $[7,29,48-50,52]$ or with pre-cancerous lesions is controversial [10,15,30,32], and only a few studies have been conducted in Hispanic populations with gastric ulcers [50]. This is the first study to investigate the prevalence of $\operatorname{cagA}$ variants in southern Mexico. Our results show that the presence of two or more EPIYA-C repeats within the cagA gene represents a higher risk of peptic ulcers and gastric cancer. It is likely that this increase in the number of EPIYA-C repeats plays an important role in the development of such diseases in individuals from this particular geographic region. A total of $51.5 \%$ of the samples with two EPIYA-C repeats came from patients with chronic gastritis. It is likely that some of these individuals have a higher risk of cancer development [29] given that the increase in the number of EPIYA-C motifs increases the CagA phosphorylation status and its interactions with cellular proteins that induce epithelial cell elongation, cell turnover, and pro-inflammatory cytokine production, thus facilitating the development of gastric cancer [29,41]. These findings might also be related to other clinical results.

The virulence factors of $H$. pylori are important risk determinants but are not sufficient to induce the full development of severe gastroduodenal disease. The host's genetic and sociocultural factors also contribute to the risk of pre-cancerous lesions and gastric cancer $[56,57]$.

\section{Conclusions}

In conclusion, the present study shows that cagA-positive H. pylori infection is highly prevalent in patients from southern Mexico with chronic gastritis, peptic ulcers, and gastric cancer. All CagA isoforms were of the western type. The cagA allele that encodes the EPIYA-ABC pattern was most frequently observed in chronic gastritis samples, while the EPIYA-ABCC isoform predominated in peptic ulcer and gastric cancer samples. CagA variants that encode two or more EPIYA-C motifs are associated with peptic ulcer and gastric cancer. Likely, either the EPIYA$\mathrm{ABCC}$ sequence or patterns with two or more EPIYA-C motifs are a risk marker for severe gastric pathologies. 


\section{Competing interests}

The authors declare that they have no competing interests.

\section{Authors' contributions}

GFT and ARR designed and coordinated the research. SR and JS conducted the endoscopic study and obtained patient biopsies. FOBA and TMP conducted the research. MAR and $\mathrm{OMH}$ conducted the sequencing reactions. OPZ conducted the bioinformatics analysis. FOBA, BIA, and GFT analyzed the data and wrote the manuscript. All authors read and approved the final manuscript

\section{Acknowledgements}

The authors wish to thank gastroenterologists as well as the nurses and support personnel who assisted in obtaining samples. We also want to thank Martín O. Morrugares Ixtepan, Specialist in Pathological Anatomy with subspecialty in Oncological Pathology, who was responsible for the histopathological diagnosis. Special thanks to Dr. Victor Hugo Garzon Barrientos and Dr. José Eduardo Navarro Zarza, who approved the project. This study was supported by the Autonomous University of Guerrero (2010-2012 funding period) and the Secretariat of Public Education (via PROMEP 2007 key PROMEP UAGUER-EXB-096 and PIFI-2010 support for ex-fellows). During the investigation, Tomás Manuel Poblete and Fredy Omar Beltrán were fellows of CONACYT, Mexico.

\section{Author details}

${ }^{1}$ Clinical Research Laboratory, Academic Unit of Chemical-Biological Sciences, Autonomous University of Guerrero, Chilpancingo, Guerrero C.P. 39090, Mexico. ${ }^{2}$ State Institute of Oncology "Dr. Arturo Beltrán Ortega", Acapulco, Guerrero C. P. 39570, Mexico. ${ }^{3}$ General Hospital "Dr. Raymundo Abarca Alarcón", Chilpancingo, Guerrero C.P. 39090, Mexico. "Department of Chronic Infections and Cancer, Infectious Diseases Research Center, National Institute of Public Health, Av. Universidad No. 655, Cerrada los Pinos y Caminera, Colonia Santa María Ahuacatitlan, Cuernavaca, Morelos C.P. 62100, Mexico. ${ }^{5}$ Laboratory of Molecular Biomedicine, Academic Unit of Chemical-Biological Sciences, Autonomous University of Guerrero, Chilpancingo, Guerrero C.P. 39090, Mexico

Received: 13 August 2014 Accepted: 17 December 2014 Published online: 24 December 2014

\section{References}

1. de Martel C, Forman D, Plummer M: Gastric cancer: epidemiology and risk factors. Gastroenterol Clin N Am 2013, 42:219-40.

2. Wroblewski LE, Peek RM Jr, Wilson KT: Helicobacter pylori and gastric cancer: factors that modulate disease risk. Clin Microbiol Rev 2010, 23:713-39.

3. Hatakeyama M: Helicobacter pylori and gastric carcinogenesis. J Gastroenterol 2009, 44:239-48.

4. Kuipers EJ, Perez-Perez Gl, Meuwissen SG, Blaser MJ: Helicobacter pylori and atrophic gastritis: importance of the cagA status. J Natl Cancer Inst 1995, 87:1777-80

5. Proenca Modena JL, Lopes Sales Al, Olszanski Acrani G, Russo R, Vilela Ribeiro MA, Fukuhara Y, da Silveira WD, Modena JL, de Oliveira RB, Brocchi M: Association between Helicobacter pylori genotypes and gastric disorders in relation to the cag pathogenicity island. Diagn Microbiol Infect Dis 2007, 59:7-16.

6. Secka O, Antonio M, Berg DE, Tapgun M, Bottomley C, Thomas V, Walton R, Corrah T, Thomas JE, Adegbola RA: Mixed infection with cagA positive and cagA negative strains of Helicobacter pylori lowers disease burden in The Gambia. PLoS One 2011, 6:e27954.

7. Basso D, Zambon CF, Letley DP, Stranges A, Marchet A, Rhead JL, Schiavon S, Guariso G, Ceroti M, Nitti D, Rugge M, Plebani M, Atherton JC: Clinical relevance of Helicobacter pylori cagA and vacA gene polymorphisms. Gastroenterology 2008, 135:91-9.

8. Camorlinga-Ponce M, Flores-Luna L, Lazcano-Ponce E, Herrero R, BernalSahagun F, Abdo-Francis JM, Aguirre-Garcia J, Munoz N, Torres J: Age and severity of mucosal lesions influence the performance of serologic markers in Helicobacter pylori-associated gastroduodenal pathologies. Cancer Epidemiol Biomarkers Prev 2008, 17:2498-504.

9. Figura N, Vindigni C, Covacci A, Presenti L, Burronim D, Vernillo R, Banducci T, Roviello F, Marrelli D, Biscontri M, Kristodhullu S, Gennari C, Vaira D: cagA positive and negative Helicobacter pylori strains are simultaneously present in the stomach of most patients with non-ulcer dyspepsia: relevance to histological damage. Gut 1998, 42:772-8.

10. Flores-Luna L, Camorlinga-Ponce M, Hernandez-Suarez G, Kasamatsu E, Martinez ME, Murillo R, Lazcano E, Torres J: The utility of serologic tests as biomarkers for Helicobacter pylori-associated precancerous lesions and gastric cancer varies between Latin American countries. Cancer Causes Control 2013, 24:241-8.

11. Huang JQ, Zheng GF, Sumanac K, Irvine EJ, Hunt RH: Meta-analysis of the relationship between cagA seropositivity and gastric cancer. Gastroenterology 2003, 125:1636-44.

12. Palli D, Masala G, Del Giudice G, Plebani M, Basso D, Berti D, Numans ME, Ceroti M, Peeters PH, de Mesquita HB B, Buchner FL, Clavel-Chapelon F, Boutron-Ruault MC, Krogh V, Saieva C, Vineis P, Panico S, Tumino R, Nyrén O, Simán H, Berglund G, Hallmans G, Sanchez MJ, Larrãnaga N, Barricarte A, Navarro C, Quiros JR, Key T, Allen N, Bingham S: CagA+ Helicobacter pylori infection and gastric cancer risk in the EPIC-EURGAST study. Int J Cancer 2007, 120(4):859-67.

13. Sahara S, Sugimoto M, Vilaichone RK, Mahachai V, Miyajima H, Furuta T, Yamaoka Y: Role of Helicobacter pylori cagA EPIYA motif and vacA genotypes for the development of gastrointestinal diseases in Southeast Asian countries: a meta-analysis. BMC Infect Dis 2012, 12:223.

14. Satomi S, Yamakawa A, Matsunaga S, Masaki R, Inagaki T, Okuda T, Suto H, Ito Y, Yamazaki Y, Kuriyama M, Keida Y, Kutsumi H, Azuma T: Relationship between the diversity of the cagA gene of Helicobacter pylori and gastric cancer in Okinawa, Japan. J Gastroentero/ 2006, 41:668-73.

15. Sicinschi LA, Correa P, Peek RM, Camargo MC, Piazuelo MB, Romero-Gallo J, Hobbs SS, Krishna U, Delgado A, Mera R, Bravo LE, Schneider BG: CagA Cterminal variations in Helicobacter pylori strains from Colombian patients with gastric precancerous lesions. Clin Microbiol Infect 2010, 16:369-78.

16. Matteo MJ, Granados G, Perez CV, Olmos M, Sanchez C, Catalano M: Helicobacter pylori cag pathogenicity island genotype diversity within the gastric niche of a single host. J Med Microbiol 2007, 56(Pt 5):664-9.

17. Nomura AM, Lee J, Stemmermann GN, Nomura RY, Perez-Perez Gl, Blaser MJ: Helicobacter pylori CagA seropositivity and gastric carcinoma risk in a Japanese American population. J Infect Dis 2002, 186:1138-44.

18. Backert S, Ziska E, Brinkmann V, Zimny-Arndt U, Fauconnier A, Jungblut PR, Naumann M, Meyer TF: Translocation of the Helicobacter pylori CagA protein in gastric epithelial cells by a type IV secretion apparatus. Cell Microbiol 2000, 2:155-64.

19. Rohde M, Puls J, Buhrdorf R, Fischer W, Haas R: A novel sheathed surface organelle of the Helicobacter pylori cag type IV secretion system. Mol Microbiol 2003, 49:219-34.

20. Mueller D, Tegtmeyer N, Brandt S, Yamaoka Y, De Poire E, Sgouras D, Wessler S, Torres J, Smolka A, Backert S: c-Src and c-Abl kinases control hierarchic phosphorylation and function of the CagA effector protein in Western and East Asian Helicobacter pylori strains. J Clin Invest 2012, 122:1553-66.

21. Selbach M, Moese S, Hauck CR, Meyer TF, Backert S: Src is the kinase of the Helicobacter pylori CagA protein in vitro and in vivo. J Biol Chem 2002, 277:6775-8.

22. Tegtmeyer N, Backert S: Role of Abl and Src family kinases in actincytoskeletal rearrangements induced by the Helicobacter pylori CagA protein. Eur J Cell Biol 2011, 90:880-90.

23. Murata-Kamiya N: Pathophysiological functions of the CagA oncoprotein during infection by Helicobacter pylori. Microbes Infect 2011, 13:799-807.

24. Backert S, Tegtmeyer N, Selbach M: The versatility of Helicobacter pylori CagA effector protein functions: the master key hypothesis. Helicobacter 2010, 15:163-76.

25. Higashi H, Tsutsumi R, Muto S, Sugiyama T, Azuma T, Asaka M, Hatakeyama M: SHP-2 tyrosine phosphatase as an intracellular target of Helicobacter pylori CagA protein. Science 2002, 295:683-6.

26. Suzuki M, Kiga K, Kersulyte D, Cok J, Hooper CC, Mimuro H, Sanada T, Suzuki S, Oyama M, Kozuka-Hata H, Kamiya S, Zou QM, Gilman RH, Berg DE, Sasakawa C: Attenuated CagA oncoprotein in Helicobacter pylori from Amerindians in Peruvian Amazon. J Biol Chem 2011, 286:29964-72.

27. Suzuki M, Mimuro H, Kiga K, Fukumatsu M, Ishijima N, Morikawa H, Nagai S, Koyasu S, Gilman RH, Kersulyte D, Berg DE, Sasakawa C: Helicobacter pylori CagA phosphorylation-independent function in epithelial proliferation and inflammation. Cell Host Microbe 2009, 5:23-34.

28. Yamazaki S, Yamakawa A, Ito Y, Ohtani M, Higashi H, Hatakeyama M, Azuma T: The CagA protein of Helicobacter pylori is translocated into epithelial 
cells and binds to SHP-2 in human gastric mucosa. J Infect Dis 2003, 187:334-7.

29. Quiroga AJ, Huertas A, Combita AL, Bravo MM: Variation in the number of EPIYA-C repeats in CagA protein from Colombian Helicobacter pylori strains and its ability middle to induce hummingbird phenotype in gastric epithelial cells. Biomedica 2010, 30:251-8.

30. Salih BA, Bolek BK, Arikan S: DNA sequence analysis of cagA $3^{\prime}$ motifs of Helicobacter pylori strains from patients with peptic ulcer diseases. J Med Microbiol 2010, 59(Pt 2):144-8.

31. Camorlinga-Ponce M, Perez-Perez G, Gonzalez-Valencia G, Mendoza I, Penaloza-Espinosa R, Ramos I, Kersulyte D, Reyes-Leon A, Romo C, Granados J, Muñoz L, Berg DE, Torres J: Helicobacter pylori genotyping from American indigenous groups shows novel Amerindian vacA and cagA alleles and Asian. African and European admixture. PLoS One 2011, 6:e27212.

32. Bosques-Padilla FJ, Tijerina-Menchaca R, Perez-Perez Gl, Flores-Gutierrez JP, Garza-Gonzalez E: Comparison of Helicobacter pylori prevalence in symptomatic patients in northeastern Mexico with the rest of the country: its association with gastrointestinal disease. Arch Med Res 2003, 34:60-3.

33. Lopez-Carrillo L, Camargo MC, Schneider BG, Sicinschi LA, HernandezRamirez RU, Correa P, Cebrian ME: Capsaicin consumption, Helicobacter pylori CagA status and IL1B-31C > T genotypes: a host and environment interaction in gastric cancer. Food Chem Toxicol 2012, 50:2118-22.

34. Lopez-Carrillo L, Torres-Lopez J, Galvan-Portillo M, Munoz L, Lopez Cervantes M: Helicobacter pylori-CagA seropositivity and nitrite and ascorbic acid food intake as predictors for gastric cancer. Eur J Cancer 2004, 40:1752-9.

35. Sicinschi LA, Lopez-Carrillo L, Camargo MC, Correa P, Sierra RA, Henry RR, Chen J, Zabaleta J, Piazuelo MB, Schneider BG: Gastric cancer risk in a Mexican population: role of Helicobacter pylori CagA positive infection and polymorphisms in interleukin-1 and -10 genes. Int J Cancer 2006, 118:649-57.

36. Torres J, Lopez L, Lazcano E, Camorlinga M, Flores L, Munoz O: Trends in Helicobacter pylori infection and gastric cancer in Mexico. Cancer Epidemiol Biomarkers Prev 2005, 14:1874-7.

37. Reyes-Leon A, Atherton JC, Argent RH, Puente JL, Torres J: Heterogeneity in the activity of Mexican Helicobacter pylori strains in gastric epithelial cells and its association with diversity in the cagA gene. Infect Immun 2007, 75:3445-54.

38. Rizzato C, Torres J, Plummer M, Munoz N, Franceschi S, Camorlinga-Ponce M, Fuentes-Panana EM, Canzian F, Kato I: Variations in Helicobacter pylori cytotoxin-associated genes and their influence in progression to gastric cancer: implications for prevention. PLoS One 2012, 7:e29605.

39. Green MR, Sambrook J: Molecular cloning: a laboratory manual. New York: Cold Spring Harbor Laboratory Press; 2012.

40. Roman-Roman A, Giono-Cerezo S, Camorlinga-Ponce M, Martinez-Carrillo DN, Loaiza-Loeza S, Fernandez-Tilapa G: vacA genotypes of Helicobacter pylori in the oral cavity and stomach of patients with chronic gastritis and gastric ulcer. Enferm Infecc Microbiol Clin 2013, 31:130-5.

41. Argent RH, Zhang $Y$, Atherton JC: Simple method for determination of the number of Helicobacter pylori CagA variable-region EPIYA tyrosine phosphorylation motifs by PCR. J Clin Microbiol 2005, 43:791-5.

42. Schmidt HM, Goh KL, Fock KM, Hilmi I, Dhamodaran S, Forman D, Mitchell $\mathrm{H}$ : Distinct cagA EPIYA motifs are associated with ethnic diversity in Malaysia and Singapore. Helicobacter 2009, 14:256-63.

43. Tamura K, Peterson D, Peterson N, Stecher G, Nei M, Kumar S: MEGA5: molecular evolutionary genetics analysis using maximum likelihood, evolutionary distance, and maximum parsimony methods. Mol Biol Evol 2011, 28:2731-9.

44. Queiroz DM, Silva Cl, Goncalves MH, Braga-Neto MB, Fialho AB, Fialho AM, Rocha GA, Rocha AM, Batista SA, Guerrant RL, Lima AA, Braga LL: Higher frequency of cagA EPIYA-C phosphorylation sites in $\mathrm{H}$. pylori strains from first-degree relatives of gastric cancer patients. BMC Gastroenterol 2012, 12:107.

45. Paniagua GL, Monroy E, Rodriguez R, Arroniz S, Rodriguez C, Cortes JL, Camacho A, Negrete E, Vaca S: Frequency of vacA, cagA and babA2 virulence markers in Helicobacter pylori strains isolated from Mexican patients with chronic gastritis. Ann Clin Microbiol Antimicrob 2009, 8:14.

46. Azuma T, Ohtani M, Yamazaki Y, Higashi H, Hatakeyama M: Meta-analysis of the relationship between CagA seropositivity and gastric cancer. Gastroenterology 2004, 126:1926-7. author reply 1927-1928.
47. Kumar S, Kumar A, Dixit VK: Diversity in the cag pathogenicity island of Helicobacter pylori isolates in populations from North and South India. J Med Microbiol 2010, 59(Pt 1):32-40.

48. Batista SA, Rocha GA, Rocha AM, Saraiva IE, Cabral MM, Oliveira RC, Queiroz DM: Higher number of Helicobacter pylori CagA EPIYA C phosphorylation sites increases the risk of gastric cancer, but not duodenal ulcer. BMC Microbiol 2011, 11:61.

49. Acosta N, Quiroga A, Delgado P, Bravo MM, Jaramillo C: Helicobacter pylori CagA protein polymorphisms and their lack of association with pathogenesis. World J Gastroenterol 2010, 16:3936-43.

50. Torres LE, Gonzalez L, Melian K, Alonso J, Moreno A, Hernandez M, Reyes O, Bermudez L, Campos J, Perez-Perez G, Rodríguez BL: EPIYA motif patterns among Cuban Helicobacter pylori CagA positive strains. Biomedica 2012, 32:23-31.

51. Kersulyte D, Kalia A, Gilman RH, Mendez M, Herrera P, Cabrera L, Velapatino B, Balqui J, Paredes Puente dela Vega F, Rodriguez Ulloa CA, Cok J, Hooper CC, Dailide G, Tamma S, Berg DE: Helicobacter pylori from Peruvian amerindians: traces of human migrations in strains from remote Amazon, and genome sequence of an Amerind strain. PLOS One 2010, 5:e15076.

52. Sgouras DN, Panayotopoulou EG, Papadakos K, Martinez-Gonzalez B, Roumbani A Panayiotou J, VanVliet-Constantinidou C, Mentis AF, Roma-Giannikou E: CagA and VacA polymorphisms do not correlate with severity of histopathological lesions in Helicobacter pylori-infected Greek children. J Clin Microbiol 2009, 47:2426-34.

53. Furuta Y, Yahara K, Hatakeyama M, Kobayashi I: Evolution of cagA oncogene of Helicobacter pylori through recombination. PLoS One 2011, 6:e23499.

54. Ishikawa S, Ohta T, Hatakeyama M: Stability of Helicobacter pylori CagA oncoprotein in human gastric epithelial cells. FEBS Lett 2009, 583:2414-8

55. Ferlay J, Shin H, Bray F, Forman D, Mathers C, Parkin D: GLOBOCAN 2008 V2.0, Cancer Incidence and Mortality Worldwide: IARC CancerBase No. 10 [Internet]. Lyon, France: International Agency for Research on Cancer; 2010. Available from: http://globocan.iarc.fr.

56. Tarkhashvili N, Chakvetadze N, Mebonia N, Chubinidze M, Bakanidze L, Shengelidze V, Mirtskhulava M, Chachava T, Katsitadze G, Gabunia U, Kordzaia D, Imnadze P, Guarner J, Sobel J: Traditional risk factors for Helicobacter pylori infection not found among patients undergoing diagnostic upper endoscopy-Republic of Georgia, 2007-2008. Int I Infect Dis 2012, 16:e697-702.

57. Wu Y, Fan Y, Jiang Y, Wang Y, Liu H, Wei M: Analysis of risk factors associated with precancerous lesion of gastric cancer in patients from eastern China: a comparative study. J Cancer Res Ther 2013, 9:205-9.

\section{Submit your next manuscript to BioMed Central and take full advantage of:}

- Convenient online submission

- Thorough peer review

- No space constraints or color figure charges

- Immediate publication on acceptance

- Inclusion in PubMed, CAS, Scopus and Google Scholar

- Research which is freely available for redistribution

Submit your manuscript at www.biomedcentral.com/submit
() Biomed Central 